3. Dreifaldt M, Mannion JD, Bodin L, Olsson H, Zagozdzon L, Souza D. The notouch saphenous vein as the preferred second conduit for coronary artery bypass grafting. Ann Thorac Surg. 2013;96:105-11.

4. Kopjar T, Dashwood MR, Dreifaldt M, de Souza DR. No-touch saphenous vein as an important conduit of choice in coronary bypass surgery. J Thorac Dis. 2018; 10(Suppl 26):S3292-6.

5. Wingo M, Gaudino M. RADIAL meta-analysis: following the rules usually pays off. J Thorac Dis. 2018;10:E787-90.

6. Song SW, Sul SY, Lee HJ, Yoo KJ. Comparison of the radial artery and saphenous vein as composite grafts in off-pump coronary artery bypass grafting in elderly patients: a randomized controlled trial. Korean Circ J. 2012;42:107-12.

https://doi.org/10.1016/j.jtcvs.2018.11.059

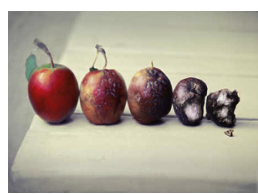

\section{APPLES REMAIN \\ APPLES NO \\ MATTER WHAT}

Reply to the Editor:

Drs Dashwood and Loesch contributed their insightful comments to the debate of graft choice in coronary artery bypass grafting (CABG). In their letter to the editor titled, "Arterial Versus Venous Conduits in Coronary Bypass Surgery: Comparing Apples With Oranges," ${ }^{1}$ they point out several considerations that may be important in relation to the harvest technique of a saphenous vein graft (SVG) (no-touch and nondistended) and argue that the results of the Radial Artery Database International Alliance (RADIAL) investigator trial ${ }^{2}$ were actually biased by not including 1 available additional controlled randomized trial. This omitted trial revealed that the no-touch SVG had superior patency to the radial artery (RA) after 3 years of follow-up. ${ }^{3}$ It appears that by adding this randomized trial to the other 5 trials with the protocol-driven angiography included in the RADIAL trial, the difference in risk of graft occlusion between the RA and the SVG would disperse. ${ }^{4}$ Furthermore, and interestingly, it appears that the only trial employing the no-touch SVG harvest technique, which was accepted to be included in the RADIAL trial, ${ }^{5}$ reported a similar patency rate of the SVG to the RA. It is difficult to ignore those arguments, especially after the recent publication by Gaudino and colleagues ${ }^{6}$ of a large meta-analysis comparing the RA with the SVG, and with the inclusion of the RADIAL investigator randomized trials. This meta-analysis revealed the unexplained superior survival at 6.6 years of the RA compared with the SVG group, with no difference in the rates of myocardial infarction or repeat revascularization. This is in complete contrast with the RADIAL investigator trial results.

Dashwood and Loesch, ${ }^{1}$ although currently being commended for their persistency, should be careful with their enthusiasm. Stating that "an atraumatic, no-touch technique of harvesting the saphenous vein provides an improved graft with a long-term patency comparable to the internal thoracic artery at 16 years," based on an anecdotal, small, single-center observational cohort trial (of the

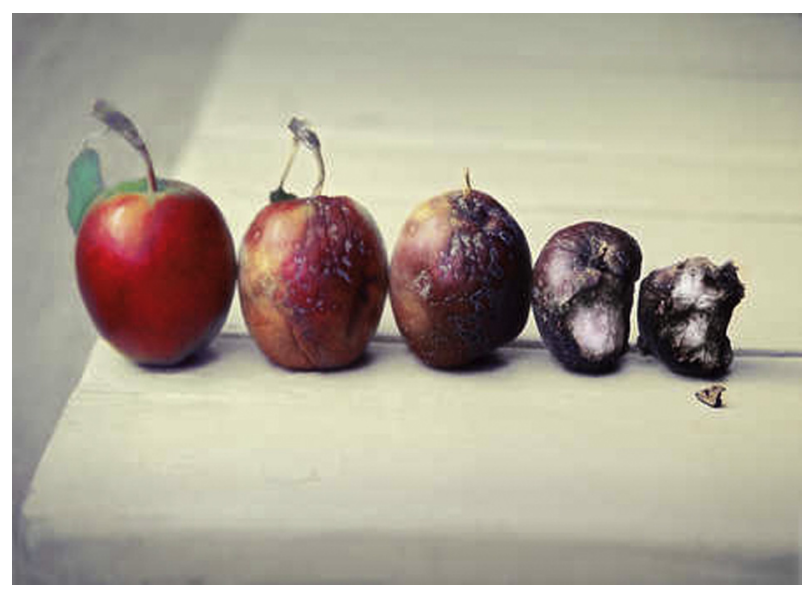

FIGURE 1. An apple remains an apple, and a saphenous vein graft will never become an arterial graft.

original 168 patients, 71 were lost to follow-up, including 34 who died of unknown reasons) ${ }^{8}$ that suffered from major design and statistical shortcomings, is unacceptable.

Recently, there have been many efforts to shift coronary practice back to the days of Favaloro, 50 years ago, with the frequent use of SVG: Endoscopic vein harvest, to provide improved cosmetic outcome (perhaps in the price of reduced patency and survival?), new SVG wrapping devices to prevent vein graft dilatation and improve patency, ${ }^{9}$ and many other additional efforts to preserve "the art of saphenous vein grafting" ${ }^{10}$ (These authors should be commended for aiming to use bilateral internal thoracic artery [ITA] routinely.)

All the aforementioned efforts ignore the simple fact that an apple will remain an apple (Figure 1) no matter how you peel it, and an SVG will never become an arterial graft. Obviously, it is beyond the scope of this letter to detail the well-known pathophysiology of SVG failure ${ }^{11}$ and the physiologic and morphologic data for ITA patency. ${ }^{12}$ The argument that saphenous veins are still the "main horsepower" for CABG, as if this would be predestination and would only require improvement, is futile. This can be changed if decisions would be based on critical analyses and hard data. ${ }^{13}$ As I recall, when participation in the Randomized comparison of the clinical Outcome of single versus Multiple Arterial grafts (ROMA) trial ${ }^{14}$ was proposed to Mayo Clinic, Dr Richard Daly, one of my mentors, asked me (exact quote): "What group would be randomized (for whom there would be reasonable equipoise)? If I think a patient is a candidate for multiarterial CABG, I would want to do it, and not risk him with left ITA/SVG in randomization, as it is hard to deny the data that we have."

It needs to be clear that some medical centers around the world are beyond the turning point with regard to the use of multiarterial grafting. As the recent arguments of a "steep learning curve" and "unique results in certain hands" are 
Author has nothing to disclose with regard to commercial support.

more frequently used in relation to coronary surgery techniques, and with all the respect and empowerment of randomized trials, ${ }^{15}$ it seems to be "nonscientific" to ignore the mounting hard data on the advantages of multiarterial grafting.

Favaloro ${ }^{16}$ stated in an editorial published 47 years ago: "Generally, editorials are written to present personal views on a specific subject. With few exceptions, they seldom add to scientific knowledge. Usually, the author is more preoccupied with flaunting his rhetoric and literary style than in concentrating on basic facts." We should sincerely question ourselves if this still applies only to editorials and if used for rhetoric purposes only.

\section{Chaim Locker, MD \\ Department of Cardiovascular Surgery Mayo Clinic \\ Rochester, Minn}

\section{References}

1. Dashwood MR, Loesch A. Arterial versus venous conduits in coronary bypass surgery: comparing apples with oranges. J Thorac Cardiovasc Surg. 2019;157:253-4.

2. Gaudino M, Benedetto U, Fremes S, Biondi-Zoccai G, Sedrakyan A, Puskas JD, et al. Radial-artery or saphenous-vein grafts in coronary-artery bypass surgery. $N$ Engl J Med. 2018;378:2069-77.

3. Dreifaldt M, Mannion JD, Bodin L, Olsson H, Zagozdon L, Souza D. The notouch saphenous vein as the preferred second conduit for coronary artery bypass grafting. Ann Thorac Surg. 2013;96:105-11.

4. Kopjar T, Dashwood MR, Dreifaldt M, Souza D. No-touch saphenous vein as an important conduit of choice in coronary bypass surgery. J Thorac Dis. 2018; 10(suppl 26):S3292-6.

5. Song SW, Sul SY, Lee HJ, Yoo KJ. Comparison of the radial artery and saphenous vein as composite grafts in off-pump coronary artery bypass grafting in elderly patients: a randomized controlled trial. Korean Circ J. 2012; 42:107-12.

6. Gaudino M, Rahouma M, Abourab A, Leonard J, Kamel M, Di Franco A, et al. Radial artery versus saphenous vein as the second conduit for coronary artery bypass surgery: a meta-analysis. J Thorac Cardiovasc Surg. 2019;157:1819-25.

7. Locker C. Commentary: If RITA did not exist it would be necessary to invent it so if you can't beat them join them. J Thorac Cardiovasc Surg. 2019;157:1826-8.

8. Samano N, Geijer H, Liden M, Fremes S, Bodin L, Souza D. The no-touch saphenous vein for coronary artery bypass grafting maintains a patency after 16 years comparable to the left internal thoracic artery: a randomized trial. J Thorac Cardiovasc Surg. 2015;150:880-8.

9. Taggart DP, Amin S, Djordjevic J, Oikonomou EK, Thomas S, Kampoli AM, et al. A prospective study of external stenting of saphenous vein grafts to the right coronary artery: the VEST II study. Eur $J$ Cardiothorac Surg. 2017;51:952-8.

10. Moshkowitz Y, Raanani E. The art of saphenous vein grafting and patency maintenance. J Thorac Cardiovasc Surg. 2016;151:300-2.

11. Harskamp RE, Lopes RD, Baisden CE, deWinter RJ, Alexander JH. Saphenous vein graft failure after coronary artery bypass surgery: pathophysiology management and future directions. Ann Surg. 2013;257:824-33.

12. Kurlansky P. Multiple arterial grafting for coronary revascularization: "a guide for the preplaxed" Trends Cardiovasc Med. 2016;26:616-23.

13. Saran N, Locker C, Joyce DL. Expanding the use of bilateral internal thoracic artery: yes we can. J Thorac Cardiovasc Surg. 2018;156:1003-4.
14. Gaudino M, Alexander JH, Bakaeen FG, Ballman K, Barili F, Calafiore AM, et al. Randomized comparison of the clinical outcome of single versus multiple arterial grafts: the ROMA trial-rationale and study protocol. Eur J Cardiothorac Surg. 2017;52:1031-40.

15. Gaudino M, Mack JM, Taggart DP. Additional arterial conduits in coronary artery bypass surgery: finally coming of age. J Thorac Cardiovasc Surg. 2018; 156:541-3.

16. Favaloro RG. Surgical treatment of coronary arteriosclerosis by the saphenous vein graft technique: critical analysis. Am J Cardiol. 1971;28:493-5.

https://doi.org/10.1016/j.jtcvs.2018.12.005

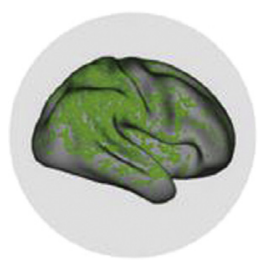

\section{REMOTE ISCHEMIC PRECONDITIONING INDUCES} NEUROPROTECTION ASSESSED BY CEREBRAL MAGNETIC RESONANCE IMAGING: ESSENTIAL ROLE OF BLOOD PRESSURE AND HEMOGLOBIN LEVELS

\section{To the Editor:}

We read with great interest the paper from Gasparovic and the colleagues ${ }^{1}$ in which they randomized 33 remote ischemic preconditioning-treated patients and 33 control patients undergoing first-time isolated coronary artery bypass grafting and assessed the cerebral structure and function by magnetic resonance imaging. They found a lowered brain ischemic volume in remote ischemic preconditioning group than that in the control group.

Brain ischemic injury during on-pump coronary artery bypass grafting is still a serious complication, ${ }^{2,3}$ which has been proposed to several contributing causes: cardioembolic, thrombotic, hemorrhagic, lacunar, and hypoperfused. ${ }^{4,5}$ The hypoperfused factor for the brain ischemic volume is the easiest one to be monitored and prevented intraoperatively. As known to all, the cerebral oxygen supply includes the blood pressure, hemoglobin level, and saturation of arterial oxygen. Nevertheless, this study did not reveal information concerning the perioperative strategies for managing blood pressure and hemoglobin level. Hence, we wonder whether the perioperative situation (pre-bypass, intra-bypass, and post-bypass) of the 2 essential factors of the 2 groups are similar and unbiased.

Baohui Lou, PhD
Chenghui Zhou, PhD
a Department of Radiology
Beijing Hospital
National Center of Gerontology
Beijing, China
bepartment of Anesthesiology
State Key Laboratory of Cardiovascular Disease
Fuwai Hospital
National Center for Cardiovascular Diseases

